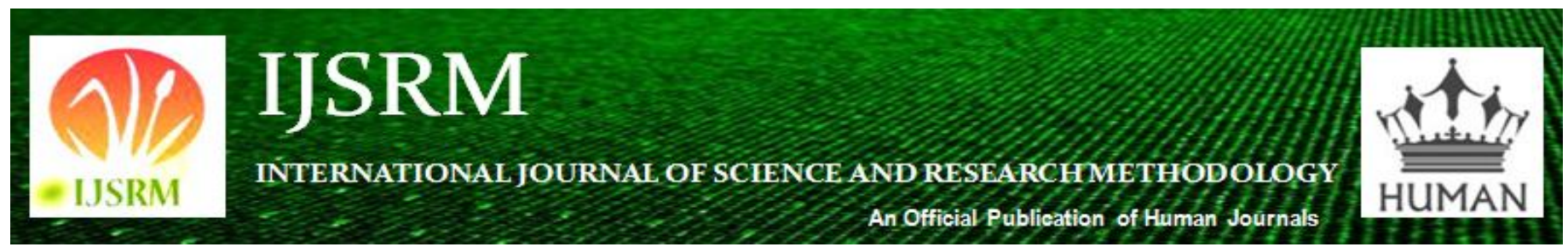

Human Journals

Research Article

November 2020 Vol.:17, Issue:1

(C) All rights are reserved by Janak Kumar Thapa et al.

\title{
Prevalence and Risk Factors of Hypertension among Elderly Population in Social Welfare Center Old Age Home, Pashupati, Kathmandu
}

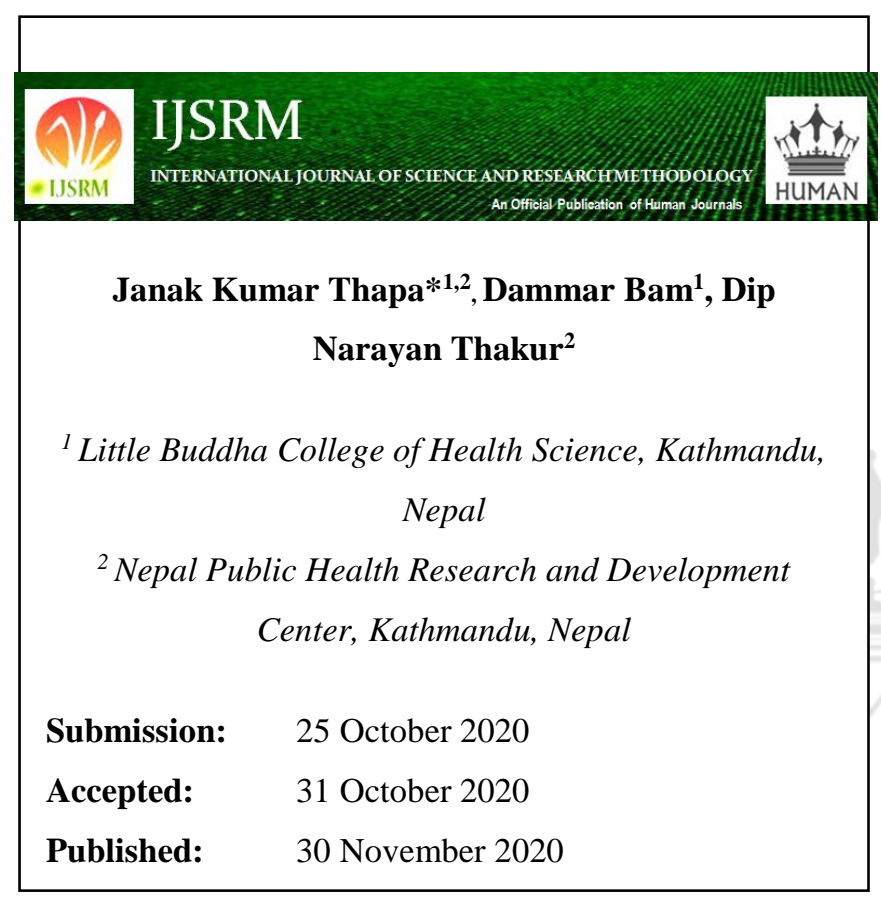

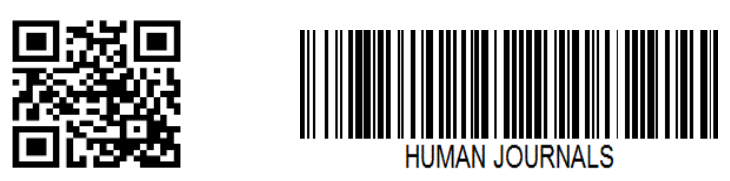

www.ijsrm.humanjournals.com
Keywords: Hypertension, Associated Risk Factors, prevalence, Elderly population

\section{ABSTRACT}

Background: Hypertension is a chronic condition of concern due to its role in causing coronary heart disease, stroke, and other vascular complications. It is one of the most important reasons behind premature death in a developing country. Many Factors like Socio-Demographic, economic, Educational, and behaviorrelated factors influence hypertension. The study's objective was to identify the prevalence and risk factors of hypertension among the elderly population in Social Welfare Center Old Age Home Pashupati, Kathmandu. Methodology: A cross-sectional population-based study was carried out in Social Welfare Center Old Age Home Pashupati, Kathmandu. Among 109 subjects of people aged 60 and above were selected through a purposive sampling technique and a census was done. A semi-structured questionnaire was used for collecting data, and a sphygmomanometer was used to measure the blood pressure. Results: Among the 109 respondents involved in the study, the mean age was 74 years. The prevalence of hypertension among the elderly was 13.8 percent, 19.6 percent among males, and 9.5 percent among females. In Marital status, Married elderly was significantly associated with hypertension. Married elderly were 3.5 times more likely to be hypertensive ( $\mathrm{COR}=3.583,95 \%$ $\mathrm{CI}=1.027-12.504)$ compared to separated (divorced, widow). In health-related information, bad health status was 3.7 times more likely to be hypertensive $(\mathrm{COR}=3.773,95 \% \mathrm{CI}=1.087-13.091)$ compared to good health status. Respondents who know the correct answer about hypertension were four times more likely to be hypertensive $(\mathrm{COR}=4.065,95 \% \mathrm{CI}=1.279-12.919)$ compared to those who did know about the incorrect answer. Conclusion: The prevalence of hypertension is among these elderlies was lower compared to the national average. However, they need regular monitoring and health checkup. The study also recommends counseling on a positive marital relationship for the elderly residing in an old-age home. The study also recommends further studies with larger samples. 


\section{INTRODUCTION}

Hypertension is a chronic condition of concern due to its role in the causation of coronary heart disease, stroke, and other vascular complications. It is the commonest cardiovascular disorder, posing a major public health challenge to the socio-economic and epidemiological transition population. It is one of the major risk factors for cardiovascular mortality, which accounts for 20$50 \%$ of all death. $(1,2)$

Hypertension is known as high or raised blood pressure, and also as a silent killer disease, is a condition in which the blood vessels have persistently raised pressure. It is a major public health problem in developing countries like Nepal. It is a precursor to major diseases like myocardial infarction, stroke, and renal failure etc. (3) Individuals were classified as hypertensive if their systolic blood pressure (SBP) was $140 \mathrm{mmHg}$ or higher and if their diastolic blood pressure (DBP) was $90 \mathrm{mmHg}$ or higher, according to the cutoff points recommended by WHO (WHO 1999). (4)

Hypertension is a major global public health problem. LMIC contribute nearly two-thirds of the mortality attributable to hypertension. It is in increasing trend in the South-Asian population. Several studies conducted in hypertension suggested that its onset occurs in the early life stage and is often associated with many CVDs risk factors. (5)

High blood pressure is one of the most important reasons behind premature death worldwide killing 9.4 million people every year globally. The highest prevalence of raised blood pressure was found in the African region, i.e., 46\%. In the South -East Asia region, 36\% of adults have hypertension. Nepal reported $2^{\text {nd }}$ highest proportion of hypertensive people after Afghanistan. In this region, one in three adults has high blood pressure. (6) Hypertension is one of the most important risk factors for cardiovascular and renal diseases. Its prevalence is in increasing trend. Essential hypertension was defined as a systolic blood pressure that is persistently $\geq 140 \mathrm{mmHg}$, or a diastolic blood pressure persistently $\geq 90 \mathrm{mmHg}$, when an average of each is measured at every visit using at least two values. (7)

Although hypertension is not considered to be part of the normal aging process as per epidemiological evidence, age is linked with the development of hypertension, which is the result of lifestyle factor, stress, genetic disposition, etc.(8) Those who are diagnosed may not have 
access to treatment due to various reasons and may not be able to control their illness over the long term successfully. Early initiation to control behavioral risk factors like high salt intake, tobacco use, alcohol consumption, physical inactivity, etc can reduce hypertension risk. (9)

Hypertension is a worldwide burden and is one of the leading causes of mortality. It develops lots of complications rapidly with different stages and leading to death. (10)

Hypertension is a major contributing factor for NCDs in both developed and developing countries. Although the rate of hypertension is rising in developed countries such as the USA as well as in lower- and middle-income countries (LMIC). (11)

Hypertension is a major cause of morbidity and mortality among the elderly population and most prevalent in urban areas. By the year 2020, non-communicable diseases are expected to account for 7 out of every 10 deaths in the developing regions. Current estimates on the global burden of hypertension need to be more prioritized by public health. $(12,13)$

The prevalence of hypertension is in increasing in the elderly population in Nepal. As per the study conducted in Banepa, the prevalence of hypertension in people aged 50 years and more was $44.9 \%$ (male $47.75 \%$ and female $42.73 \%$ ). (14)

\section{METHODS}

This quantitative cross-sectional study was conducted among 109 elderly staying at Social Welfare Center Old Age Home Pashupati, Kathmandu. The old age home was selected purposively and all elderly were included in the study unless they were disabled or unable to respond. A face-to-face interview using a semi-structured questionnaire was carried out to collect socio-demographic, socio-economic and behavior-related data while blood pressure was measured using Sphygmomanometer. Three blood pressure readings were taken in an interval of 5 minutes, and average blood pressure was recorded. The right arm of the subject in a sitting position was chosen for measuring blood pressure to ensure valid measurement and ensure comparability.

In this study, hypertension is defined as a persistent increase in blood pressure, systolic more than $140 \mathrm{mmHg}$, or diastolic more than $90 \mathrm{mmHg}$. 
Data were compiled, edited, and check for consistency, and duplication of data was collected before coding and entering them in epi data and exported to SPSS V.23.Frequencies and percentages were calculated to identify the descriptive analysis, and the odds ratio was calculated for bivariate analyzed data and its Confidence interval was 95\%. The study was carried from February 14 to November 16, 2019.

\section{RESULTS}

Among 109 respondents, 57.8\% were female. The respondents' mean age was a $74 \pm 6.88$ years, with their age ranging from 60 to 99 years. The majority of the respondents fall under the (71-80 year) age group (49.5\%). Out of 109 respondents, $78 \%$ were illiterate, and only $22 \%$ of respondents having literate. More than half of the population (53.2\%) consisted of chettri/Brahmin. Out of the total respondents, only $37.6 \%$ had known about hypertension. Of the total respondents, $37.6 \%$ were consumed tobacco products. Most of the respondents (67\%) work involved in moderate-intensity activities, and (85.3\%) make the right quantity of salt.

The prevalence of hypertension was $13.8 \%$ in this study. The number of non-hypertensive respondents is more than hypertensive respondents.

Table No. 1: Socio demographic variable $(\mathrm{N}=109)$

\begin{tabular}{|c|c|}
\hline Variable & Number (\%) $(\mathbf{N}=\mathbf{1 0 9})$ \\
\hline Gender & \\
\hline Male & $46(42.2)$ \\
\hline Female & $63(57.8)$ \\
\hline Age group (Year) & $36(33)$ \\
\hline $60-70$ & $54(49.5)$ \\
\hline $71-80$ & $19(17.5)$ \\
\hline Above 80 & \\
\hline Ethnicity & $58(53.2)$ \\
\hline Brahmin/Chettri & $45(41.3)$ \\
\hline Janajati & $6(5.5)$ \\
\hline Dalit & \\
\hline Educational status & $85(78)$ \\
\hline Illiterate & $24(22)$ \\
\hline Literate & \\
\hline &
\end{tabular}


Table No. 2: Category of Blood Pressure (N=109)

\begin{tabular}{|c|c|}
\hline Variable & Number (\%) (N=109) \\
\hline Non-Hypertensive & $94(86.2)$ \\
\hline Hypertensive & $15(13.8)$ \\
\hline Total & $\mathbf{1 0 9}(\mathbf{1 0 0 . 0})$ \\
\hline
\end{tabular}

\section{Analytical finding (Bi-variate Analysis): Association Between risk factors and hypertension}

The relationship between socio-demographic characteristics and hypertension. Marital status was significantly associated with hypertension, while sex, age, ethnicity, education, and occupation were not significantly associated with hypertension. Married elderly were 3.5 times more likely to be hypertensive $(\mathrm{COR}=3.583,95 \% \mathrm{CI}=1.027-12.504)$ compared to separated (divorced, widow). Unmarried elderly and separated, i.e., those who currently do not have partners, do not have a significant difference in having hypertension.

Self-rated health status and know about hypertension were significantly associated with hypertension, while knowledge levels were not significantly associated with hypertension. Bad health status was 3.7 times more likely to be hypertensive $(\mathrm{COR}=3.773,95 \% \mathrm{CI}=1.087-13.091)$ compared to good health status. Respondents who know the correct answer about hypertension were four times more likely to be hypertensive ( $\mathrm{COR}=4.065,95 \% \mathrm{CI}=1.279-12.919)$ as compared to those who did know about the incorrect answer.

Tobacco consumption level, alcohol consumption level, salt intake, fruits, vegetable intake, and physical activity level were not significantly associated with hypertension. 
Table No. 3: Relationship between the prevalence of hypertension and associated factors (N=109)

\begin{tabular}{|c|c|c|c|c|}
\hline $\begin{array}{l}\text { Characteristics } \\
\text { (Variables) }\end{array}$ & $\begin{array}{c}\text { Hypertensive } \\
\text { n (\%) }\end{array}$ & $\begin{array}{c}\text { Non-Hypertensive } \\
\text { n (\%) }\end{array}$ & OR & 95\% CI \\
\hline \multicolumn{5}{|l|}{ Age (years) } \\
\hline $60-70$ & $2(5.6)$ & $34(94.4)$ & Ref & \\
\hline $71-80$ & $9(16.7)$ & $45(83.3)$ & 3.400 & $0.689-16.766$ \\
\hline Above 80 & $4(21.1)$ & $15(78.9)$ & 4.533 & $0.747-27.503$ \\
\hline \multicolumn{5}{|l|}{ Sex } \\
\hline Male & $9(19.6)$ & $37(80.4)$ & 2.311 & $0.759-7.031$ \\
\hline Female & $6(9.5)$ & $57(90.5)$ & Ref & \\
\hline \multicolumn{5}{|l|}{ Marital status } \\
\hline Married & $10(25.0)$ & $30(75.0)$ & 3.583 & $1.027-12.504$ \\
\hline Unmarried & $1(4.5)$ & $21(95.5)$ & 0.512 & $0.054-4.869$ \\
\hline $\begin{array}{l}\text { Separated } \\
\text { (divorced, } \\
\text { widow) }\end{array}$ & $4(8.5)$ & $43(91.5)$ & Ref & \\
\hline \multicolumn{5}{|c|}{ Self-related status } \\
\hline Good & $10(10.8)$ & $83(89.2)$ & Ref & \\
\hline $\mathrm{Bad}$ & $15(31.3)$ & $11(68.8)$ & 3.773 & $1.087-13.091$ \\
\hline \multicolumn{5}{|l|}{ Knowledge Level } \\
\hline $\begin{array}{l}\text { No or Minimum } \\
\text { knowledge }\end{array}$ & $11(11.5)$ & $85(88.5)$ & Ref & \\
\hline $\begin{array}{l}\text { Adequate } \\
\text { knowledge }\end{array}$ & $4(30.8)$ & $9(69.2)$ & 3.434 & $0.904-13.047$ \\
\hline \multicolumn{5}{|c|}{ Tobacco consumption level } \\
\hline No & $8(11.8)$ & $60(88.2)$ & Ref & \\
\hline Low & $7(25.9)$ & $20(74.1)$ & 2.625 & $0.845-8.155$ \\
\hline High & $0(0.0)$ & $14(100)$ & 000 & \\
\hline \multicolumn{5}{|c|}{ Alcohol consumption level } \\
\hline No & 11(14.5) & $65(85.5)$ & 1.227 & $0.360-4.178$ \\
\hline Low & $4(12.1)$ & 29(87.9) & Ref & \\
\hline \multicolumn{5}{|l|}{ Salt intake } \\
\hline Low & 14(13.9) & $87(86.1)$ & 1.126 & $0.129-9.865$ \\
\hline High & $1(12.5)$ & $7(87.5)$ & Ref & \\
\hline \multicolumn{5}{|l|}{ Physical activity } \\
\hline Low & $9(22.5)$ & $31(77.5)$ & 3.048 & $0.996-9.333$ \\
\hline Moderate & $6(8.7)$ & 63(91.3) & Ref & \\
\hline
\end{tabular}




\section{DISCUSSION}

The study was attempted to identify the prevalence and risk factors among the elderly population in social welfare center old age home Pashupati Kathmandu. A descriptive cross-sectional study was done 10-month period which provided output similar as well as different to various studies conducted in different countries. This study offers personal accounts of total 109 respondents who were taken as study subjects above 60 years age groups, elderly people.

For the validity of the study result, the researcher self-involved in every step of the research activities. A valid and standard questionnaire had been developed. The questionnaire was semistructured, applying it in the field. Well established Sphygmomanometer was used for measuring the blood pressure of the respondents. All the procedures and methods were implemented carefully, and ethical considerations were followed strictly.

In the current study among total 109 respondents, the majority of the respondents were female, $57.8 \%$. Bhramin/Chhetri were in higher proportion $(53.2 \%)$ and regarding the occupational status, most of the respondents were homemaker with (43.1\%). Regarding marital status, (43.1\%) percent were widows/separated, followed by married (36.7\%) and unmarried (20.2\%). A similar result was found in a Community-Based Cross-Sectional Study in Municipalities of Kathmandu, Nepal, in which the total number of study participants was 587. Among them, 58.8\% were females, Brahmins comprised the largest proportion (35.1\%) and nearly half of respondents were homemakers (41.2\%).Regarding marital status, the majority (83\%) percent were married, followed by unmarried (11.6\%) and widow/separated (5.5\%).(14)

Out of total respondents (109), less than half (37.6\%) of respondents consume tobacco products, among which $(46.3 \%)$ currently consumed tobacco products daily out of 41 respondents. Regarding types of tobacco product consumption, 100\% consumed manufactured cigarettes, $(10.5 \%)$ consumed hand-rolled cigarettes, and (5.3\%) consumed cigar. Out of total respondents (29.4\%) had smoked tobacco products in the past. Almost all (99.1\%) didn't use smokeless tobacco products currently, and (91.7\%) didn't use smokeless tobacco in the past. In the study conducted by STEPS SURVEY among 45-69 years of age, 26.4\% had currently consumed tobacco products daily. Regarding types of tobacco product consumption, $81.0 \%$ consumed manufactured cigarettes, $(25.4 \%)$ consumed hand-rolled cigarette and no one consumed cigar. Out 
of total respondents $(11.3 \%)$ had smoked tobacco products in the past. The majority $73.1 \%$ didn't use smokeless tobacco products currently.(15)

According to NDHS 2016, the prevalence of hypertension among 15 and older was 40\% (NDHS 2016) but current study has a prevalence of $13.8 \%$. In a similar study conducted in Banepa Municipality, Nepal the prevalence of hypertension was higher $44.9 \% .(16,17)$

Similarly, in another study conducted in the Old population aged 80 years and above in urban South India, the prevalence of hypertension was six times higher, $83.5 \%$ than the current study.(18) Also, among a Community of Elderly Population in shanghai, the prevalence of hypertension was $59.9 \%$, which is higher than the current study. (19)

In a Community-Based Cross-Sectional Study in Municipalities of Kathmandu, more males than females had hypertension but there was no significant association between sex and hypertension. Similar findings were obtained in the present study where hypertension was slightly higher in males, but differences between these two groups were statistically not significant (associated). In the present study, marital status was associated with hypertension $(\mathrm{COR}=3.583,95 \% \mathrm{CI}=1.027$ 12.504). Also, the similar result was found in the above-mentioned studies where marital status was associated with hypertension (p-value <0.01). Ethnicity and age of elderly in the current study were not associated with hypertension but it was associated with the Community-Based Cross-Sectional Study in Municipalities of Kathmandu; however, there was no association of occupation and hypertension in both the studies (current and another study). (14)

Elderly who do not consume alcohol were higher, as in old age, drinking alcohol is prohibited but there was no significant association between alcohol consumption and hypertension. The elderly who had moderate to a high level of fruits and vegetable intake and who do low physical activity was higher, but there was no significant association between fruits and vegetable intake and physical activity level with hypertension also no association was found between tobacco consumption level and hypertension in the present study. In a community-based study conducted in municipalities of Kathmandu, similar findings were obtained with no association between fruits and vegetable intake and hypertension, but alcohol consumption, tobacco consumption, and physical activity had a significant association with hypertension. (14) 


\section{CONCLUSION:}

This study provides important information on the prevalence and associated risk factors of hypertension. The prevalence of hypertension is among these elderlies was lower compared to the national average. However, they need regular monitoring and health checkup. The study also recommends counseling on a positive marital relationship for the elderly residing in an old-age home. The study also recommends further studies with larger samples.

\section{Acknowledgment}

I would like to acknowledge the support received from Department of Public Health, Little Buddha College of Health Science and Nepal Public Health Research and Development Center (PHRD Nepal) to complete the data collection successfully.

\section{Ethics approval and consent to participate}

Ethical approval was obtained from the Nepal Health Research Council. Informed consent was obtained from each participant before including them in the study.

\section{Consent for publication}

Not applicable

\section{Competing interests}

The authors declare that they have no competing interests.

\section{Availability of data and materials}

The datasets used and/or analyzed during the current study are available from the corresponding author on reasonable request.

\section{Funding}

Not applicable. 


\section{www.ijsrm.humanjournals.com}

\section{Authors' contributions}

JKT was involved in the entire research process till the finalization of the manuscript. DB, DNT was involved in data analysis and review of the manuscript.

\section{REFERENCES}

1. K. Park-park's textbook of preventive and social medicine 23rd Edition.pdf.

2. 13-18 adult hyper.pdf.

3. Chataut J AR, Sinha NP. Prevalence and risk factors for hypertension in adults living in central development region of Nepal. JAN-MAR 2011;9(33).

4. Ministry of Health NE, and ICF International. Nepal demographic and health survey 2016.

5. Dorairaj Prabhakarana b, Panniyammakal Jeemona,b, Shreeparna Ghosha,b, Roopa Shivashankara b, Vamadevan S. Ajaya,b, Dimple Kondala,b, Ruby Gupta,b, Mohammed K. Alib c, Deepa Mohand, Viswanathan Mohand, Masood M. Kadire, Nikhil Tandonb f, Kolli Srinath Reddya,b, K.M. Venkat Narayanb, Prevalence and incidence of hypertension: Results from a representative cohort of over 16,000 adults in three cities of South-Asia. Indian Heart Journal. 2017.

6. WHO ROfS-EA. leaflet_burden_hbp_whd_2013.pdf. 2013.

7. Rabia Naseema AMA, Fiza Khan, Adiya Dossalb, Ibrahim Khana, Ammara Khana, Hannah Paulb, Hafsa Jaweda, Aisha Aslama, Faez Muhammad Syeda, Muhammad Ahsen Niazia, Shehzeen Nadeemc, Aruba Khanb, Amber Ziaa, Mohammad Hussham Arshadd. Prevalence and characteristics of resistant hypertensive patients in an Asian population. Indian Heart Journal. 2017.

8. Franklin SS. Elderly hypertensives: how are they different? Journal of clinical hypertension. 2012;14(11):779-86.

9. Organization WH. Global brief hypertension.pdf. 2013.

10. Salem H, Hasan DM, Ramesh A, El-Mageed HA, Hasan S, Ali R. Worldwide Prevalence of Hypertension: A Pooled Meta-Analysis of 1670 Studies in 71 Countries with 29.5 Million Participants. Journal of the American College of Cardiology. 2018;71(11): A1819.

11. Neupane D, McLachlan CS, Sharma R, Gyawali B, Khanal V, Mishra SR, et al. Prevalence of hypertension in member countries of South Asian Association for Regional Cooperation (SAARC): systematic review and metaanalysis. Medicine. 2014;93(13):e74.

12. Koju R MK, Gurung R, Pant P, Bedi TRS. Prevalence of Hypertension in Semi-Urban area of Nepal. NHJ. 2010;7.

13. Mills KT, Bundy JD, Kelly TN, Reed JE, Kearney PM, Reynolds K, et al. Global Disparities of Hypertension Prevalence and Control: A Systematic Analysis of Population-Based Studies From 90 Countries. Circulation. 2016;134(6):441-50.

14. Raja Ram Dhungana SJ, Achyut Raj Pandey aSD, Bihungum Bista,. Prevalence and Associated Factors of Hypertension: A Community-Based Cross-Sectional Study in Municipalities of Kathmandu, Nepal. International Journal of Hypertension. April 2016.

15. non_communicable_diseases_risk_factors_steps_survey_nepal_2013..pdf.

16. Manandhar K KR, Sinha NP, Humagain S. . Prevalence and Associated Risk Factors of Hypertension Among People Aged 50 years and more in Banepa Municipality, Nepal. Kathmandu University medical journal. 2012;10(39). 17. NDHS 16.pdf.

18. Reddy BM, Ganguly E, Sharma PK. Hypertension and its Correlates in the Oldest Old Population Aged 80 Years and Above in Urban South India. Journal of gerontology \& geriatric research. 2018;7(3).

19. Zhi-Qi Yang QZ, Ping Jiang, Song-Bai Zheng and Biao Xu. Prevalence and control of hypertension among a Community of Elderly Population in Changning District of shanghai: cross-sectional study.

Citation: Janak Kumar Thapa et al. Ijsrm.Human, 2020; Vol. 17 (1): 176-185. 